\title{
Preferential Looking in Clinical Practice: A Year's Experience
}

\author{
A. CHANDNA, C. M. PEARSON and R. M. L. DORAN \\ Bristol
}

\begin{abstract}
Summary
Preferential Looking (PL) is now a well established laboratory method of measuring visual acuity in preverbal chilren. We have evaluated the feasibility of its routine use in clinical practice. We present our methods and results obtained in 80 normal children and 36 children with visual disorder and discuss the problems encountered in applying this test.
\end{abstract}

If a young child is presented with a patterned target, such as a high contrast grating on a uniform featureless background, he will look at the target, providing he can see it and as long as it remains interesting. This behavioural response is the basis for Preferential Looking (PL), a new visual acuity test for preverbal infants. Fant $z^{(1,2,3)}$ utilised the "differential" response of the infant in this situation for the measurement of grating visual acuity and demonstrated the maturation of pattern vision in infants from birth to six months of age. In his original experiments, gratings were displayed in random order either on the left or right of the infant. An observer, who was aware of the location and spatial frequency of the target, counted the number and duration of fixations to the side of the target on each presentation. Acuity threshold was determined by varying the spatial frequency (stripewidth) of the grating and discovering the finest grating which repeatedly elicited a response.

Since then PL has become well established as a method of measuring visual acuity in preverbal infants in vision research laboratories. Procedural variations and changes in the design of the test have been introduced to increase its reliability and application to a wider age range of infants. In forced-choice preferential looking (FCPL) the observer is masked to the grating location and judges this on the basis of the infant's behaviour, when viewed through a peephole from behind the presentation. ${ }^{(4)}$ An independent scorer is needed to provide a feed-back of results and to direct the progress of the test. Other modifications have included Operant PL, in which rewards reinforce the attention of the older child and the diagnostic stripewidth method in which the infant is tested with gratings of spatial frequency appropriate to his or her age. ${ }^{(5,6,7)}$ The recently described Acuity Card procedure (ACP) ${ }^{(8-12)}$, using the Teller Acuity Cards*, relies on the subjective assessment of a nonmasked observer and does not require a scorer. The course of visual acuity develop-

Correspondence to: R. M. L. Doran, F.R.C.S. Ed., Eye Department, The General Infirmary, Great George Street, Leeds LS1 3EX. Tel.: 0532432799.

This work was supported by a grant from Bristol and Weston Health Authority and National Eye Research Centre, Bristol.

Paper presented at the Annual Congress Ophthalmological Society of the United Kingdom, April 1988.

From: University Department of Ophthalmology, Bristol Eye Hospital, Lower Maudlin Street, Bristol BS1 $2 \mathrm{LX}$ 
ment in infancy and age norms derived by PL which have been reported are in general agreement. ${ }^{(4,5,9,10)}$

For a long time clinicians have been in need of a reliable and practical method of measuring visual acuity in preverbal children. Existing clinical tests of infant vision elicit a range of responses to either a bright light, an attractive silent toy or a moving target. In general, these tests are poorly standardised and do not give a reliable measure of visual acuity. ${ }^{(13)}$

\section{Materials and Methods}

We used Teller Acuity Cards*, which have high contrast black and white gratings printed in a square patch on a plain grey background of equal average luminance (see Fig. 1). A standard set of 16 cards spans a frequency range from 0.32 to 38 cycles per $\mathrm{cm}$. in half octave steps. The cards were displayed through the central opening in a grey painted screen similar to a Punch and Judy stall (Fig. 2). Luminance was maintained above $1 \log$ $\mathrm{cd} / \mathrm{m}^{2}$. The test distance was adjusted according to the corrected post-term age of the infant. (14)

A staircase method of presentation was used to control the test. ${ }^{(15-17)}$ This involved the sequential presentation of gratings in an ascending or descending order of spatial frequency in a series of trials. A trial consisted of a pre-determined number of presentations at a particular frequency, in which correct and incorrect responses were scored. The score at the end of each trial determined the progress of the test on the staircase.

We used two varieties of staircase in both of which the test was initiated at a spatial frequency one octave lower than the normal level for the age of the infant. Initial steps on the staircase were in octaves. At or near threshold trials were conducted in relatively small half octave steps. Acuity threshold was determined as the highest spatial frequency at which the infant's correct responses were significantly above chance (80 percent), and

*Teller Acuity cards have been developed by Dr. D. Y. Teller and colleagues at the Department of Psychology, University of Washington, U.S.A. Cards obtainable from Vistech Consultants Inc., 1372 North Fairfield Road, Dayton, Ohio 45432, U.S.A.

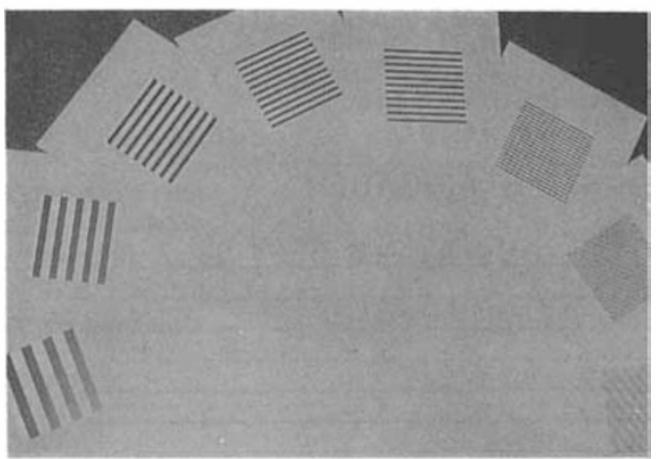

Fig. 1. Teller Acuity Cards (part of a set is shown).

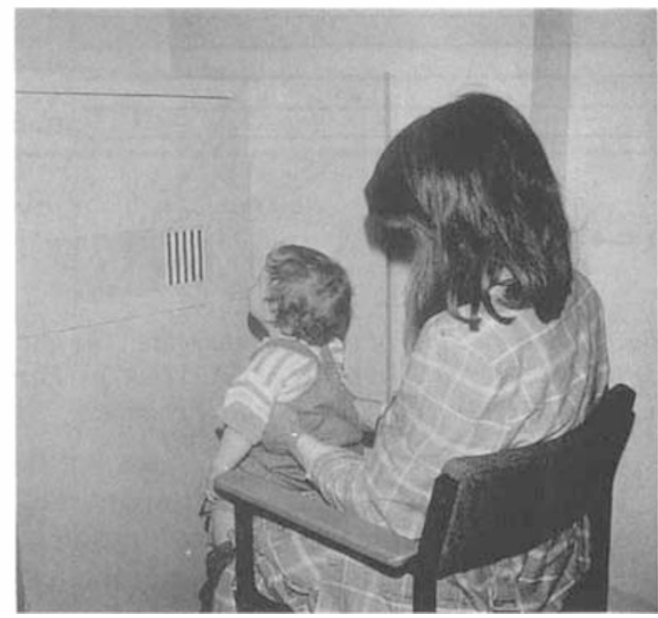

Fig. 2. Screen for presenting Teller Acuity Cards in a plain background.

at or below chance at the next higher spatial frequency. Between presentations the observer attracted the infant's attention to the centre of the display opening.

Short Staircase (2 up; 1 down): (Fig. 3). The observer was masked to the grating position for the first presentation in each trial only. Having judged its location by the infant's behaviour, the observer confirmed this by looking at the face of the card. If correct, the card was rotated by 180 degrees and presented again in order to observe a shift of attention by the infant to the other side. If obtained, the grating one octave higher on the staircase was selected. If incorrect on either of the presentations, the staircase descended. 


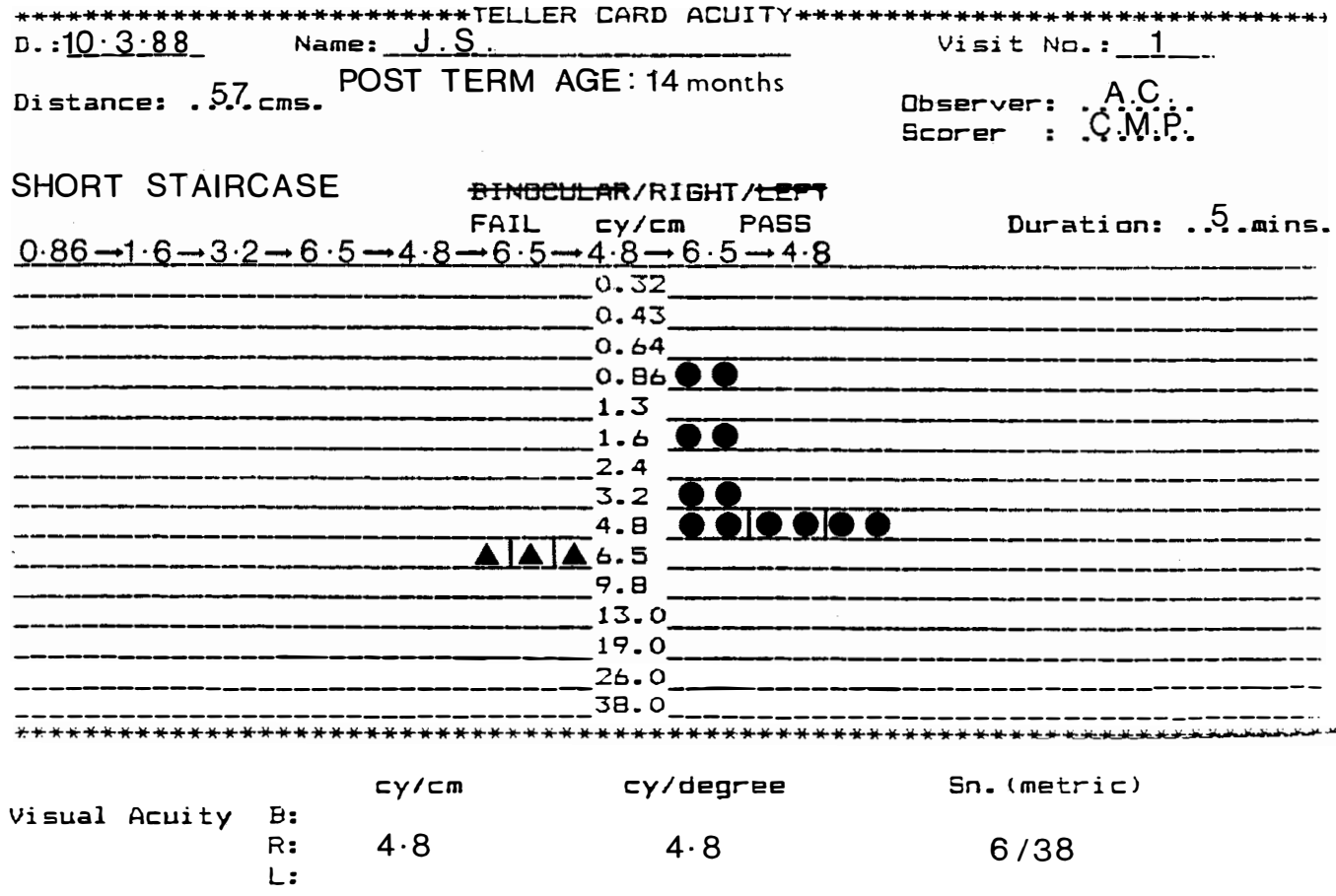

Fig. 3. An example of the short staircase. The test was initiated at 0.86 cycles $/ \mathrm{cm}$. and ascended in octave steps until a negative response at $6.5 \mathrm{cycles} / \mathrm{cm}$. Further trials were carried out in half octave steps until the score at 4.8 cycles $/ \mathrm{cm}$. was well above chance.

Long Staircase (4 up; 2 down): The observer remained masked to the location of the grating (left or right) throughout the test and a scorer conducted the test and recorded the results. Each trial consisted of five presentations. Four out of five correct responses led to a step up the scale by one octave. Two or less correct responses resulted in a step down the scale.

\section{Subjects: Group A.}

Ușing the short staircase, monocular PL acuity tests were carried out on 80 normal infants attending a well-baby clinic in general practice (Montpelier Health Centre, Bristol) for routine health checks and immunisations. They had negative birth and medical histories and underwent an ocular examination consisting of penlight examination of the pupil responses and anterior segments, cover test and ocular movements and noncycloplegic retinoscopy. Fundus examination without mydriatic was also performed where possible. Table I summarises the numbers and age distribution of the infants.
Table I P. L. acuity tests on normal children

\begin{tabular}{ccc}
\hline Age group & Mean age & $\begin{array}{c}\text { Number } \\
\text { Total No }=80\end{array}$ \\
\hline $4-8$ weeks & 6.1 weeks $( \pm 1.3)^{2}$ & 21 \\
$8-16$ weeks & 11.9 weeks $( \pm 3.0)$ & 19 \\
16 - 24 weeks & 19.1 weeks $( \pm 2.0)$ & 12 \\
6 - 12 months & 7.5 months $( \pm 1.5)$ & 18 \\
12 - 18 months & 15.5 months $( \pm 2.5)$ & 4 \\
$24-30$ months & 27.5 months $( \pm 2.5)$ & 6 \\
\hline
\end{tabular}

${ }^{1}$ Corrected age: age from due date

${ }^{2}$ One standard deviation

\section{Group B}

Thirty six children with either suspected or established visual problems were similarly tested for PL acuity at Bristol Eye Hospital without our knowledge of the ocular diagnosis (Table II). Nine were referred as suspected abnormals; 19 infants had strabismus and 8 had miscellaneous visual disorders including delayed visual maturation, sixth nerve palsy, infantile glaucoma, congenital nystagmus and cataract. Several of these cases have undergone repeated PL acuity tests. 
Table II Mean monocular P.L. acuities

\begin{tabular}{cclcl}
\hline Age group & $\mathrm{N}$ & $\begin{array}{l}\text { Right eye } \\
\text { mean (CY/DEG) }\end{array}$ & $\mathrm{N}$ & $\begin{array}{l}\text { Left eye } \\
\text { Mean (CY/DEG) }\end{array}$ \\
\hline $4-8 \mathrm{wk}$ & 15 & $0.50( \pm 0.23)^{1}$ & 14 & $0.49( \pm 0.29)^{1}$ \\
$8-16 \mathrm{wk}$ & 19 & $1.36( \pm 1.08)$ & 19 & $1.15( \pm 0.79)$ \\
$16-24 \mathrm{wk}$ & 11 & $2.13( \pm 1.20)$ & 10 & $2.36( \pm 1.01)$ \\
$6-12 \mathrm{mnth}$ & 16 & $3.72( \pm 1.55)$ & 16 & $3.69( \pm 1.29)$ \\
$12-18$ mnth & 2 & $8.00( \pm 1.58)$ & 3 & $6.45( \pm 2.90)$ \\
$24-30$ mnth & 4 & $8.87( \pm 6.81)$ & 4 & $9.95( \pm 2.53)$ \\
\hline
\end{tabular}

${ }^{1}$ One standard deviation

\section{Results: Group $A$}

Monocular PL test results for 67 right and 66 left eyes of the Group A children are presented in Figures $4 \mathrm{a}$ and $\mathrm{b}$ as a function of age. The scatter of results shows the improvement with age in the first three years of life. A variation of about 2 octaves was found in the scores at any age. The symbol which falls clearly outside this range in both graphs represents a child who was found to have a hypermetropic refractive error of +7.0 dioptres and an alternating esotropia. The superimposed lines show the sequential results from individual children tested on more than one occasion.

The mean acuity values for right and left eyes are compared for various age groups from 4 weeks to 3 years (Fig. 5). This shows a high correlation. Table II shows the mean acuity results in detail for each of six age groups.

In Figure 6, the mean interocular acuity difference in octaves is shown for the various age groups and shows least variation in the latter half of the first year.

Table III is a summary of the acuity data (Group A children) and shows the calculated mean acuity for right and left eyes, percentage of acuity results falling within one octave of the mean, the average test time (short staircase) and the percentage of successful tests achieved at each age. A successful test is one in which the infant gives reliable monocular results for both eyes at one visit. The lower success rates in the younger infants (4-8 weeks) reflect the more variable behaviour in this age group. This may also account for the same effect in the $12-18$ month old children but the number we have tested so far is small.
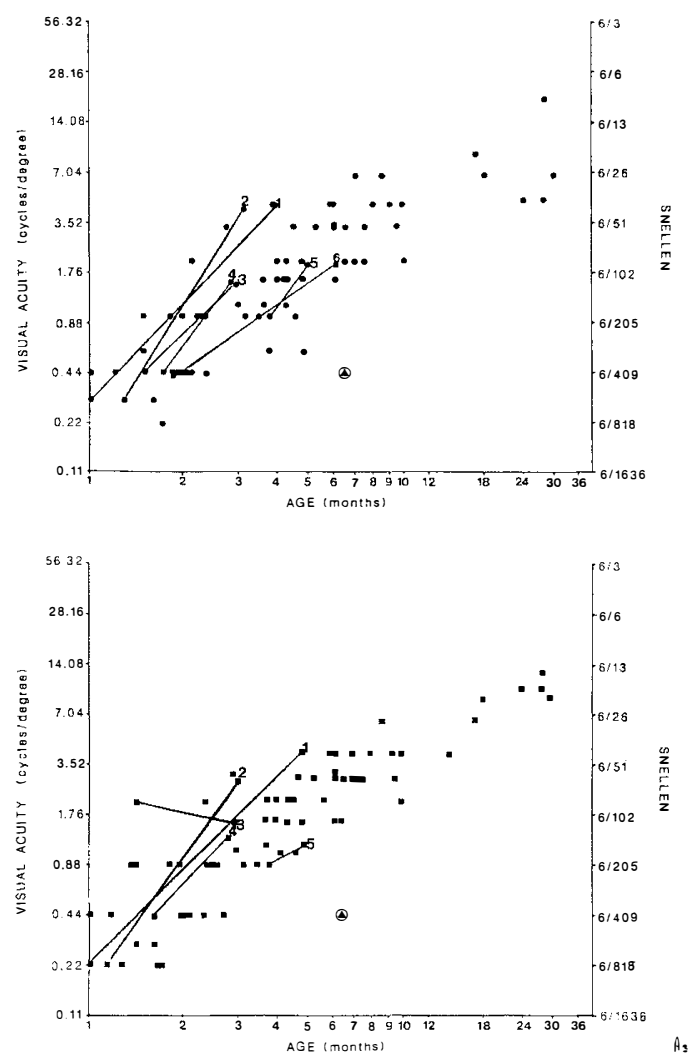

Figs $4 a$ and b. Visual acuity results. Individual scores for Right eye (filled circles and Left Eye (filled squares) of 67 normal infants. Lines represent sequential results from individual children.

\section{Group B}

Sixty one PL tests were performed, using the long staircase, on 36 infants whose ages ranged from 4 months to 34 months. The overall success rate was $72.1 \%$ and the 
average test time was 8.1 minutes for each eye (long staircase). (Table IV).

Twenty seven PL tests were repeated with a different observer (AC or CMP) to assess variability of observation. Results for the two experienced observers varied by 0 to 1.0 (mean 0.41) octaves.

Nine cases had been referred to Bristol Eye Hospital with suspected strabismus and underwent PL testing. Monocular results in every case fell within the normal range and subsequent clinical assessment revealed no ocular abnormality.

In the 19 children with strabismus, 3 had marked esotropia and poor fixation in the amblyopic eye, PL testing revealed a significant interocular difference (1.0 octave or more). Infants with alternating esotropisa showed insignificant acuity difference between the two eyes ( 0.5 octave or less).

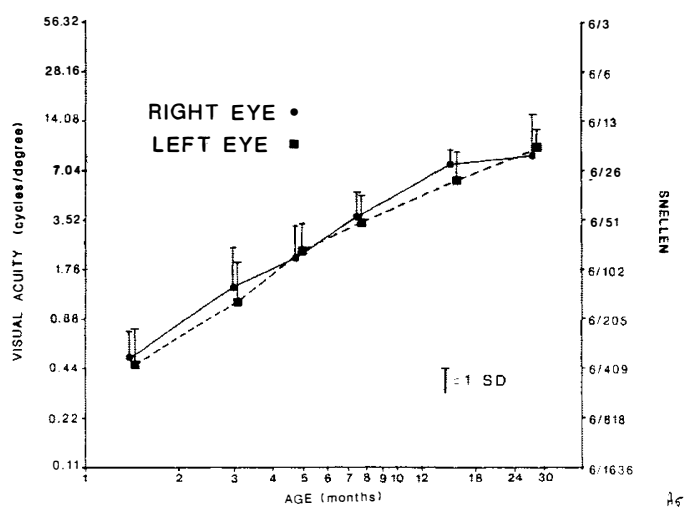

Fig. 5. Mean monocular acuities for each age group for right and left eyes.

Table III Summary of monocular P.L. acuity data: normal children

\begin{tabular}{lrlllll}
\hline Age & $N$ & $\begin{array}{l}\text { Mean acuity } \\
R \& \text { eyes } \\
(C / D E G)\end{array}$ & Snellen & $\begin{array}{l}\text { Estimates within } \\
\text { 1 octave }\end{array}$ & $\begin{array}{l}\text { Avg test time } \\
\text { monoc. S.S. } \\
\text { Min }\end{array}$ & $\begin{array}{l}\text { S.R. } \\
\%\end{array}$ \\
\hline $4-8 \mathrm{wk}$ & 21 & $0.5( \pm 0.25)^{1}$ & $6 / 360$ & $79 \%$ & 4.0 & $67 \%$ \\
$8-16 \mathrm{wk}$ & 19 & $1.3( \pm 0.94)$ & $6 / 140$ & $74 \%$ & 4.5 & $79 \%$ \\
$16-24 \mathrm{wk}$ & 12 & $2.2( \pm 1.13)$ & $6 / 80$ & $81 \%$ & 4.0 & $75 \%$ \\
$6-12 \mathrm{mnth}$ & 18 & $3.7( \pm 1.40)$ & $6 / 48$ & $94 \%$ & 4.5 & $100 \%$ \\
$12-18 \mathrm{mnth}$ & 4 & $7.1( \pm 2.35)$ & $6 / 24$ & $75 \%$ & 5.0 & $50 \%$ \\
$24-30 \mathrm{mnth}$ & 6 & $9.41( \pm 4.80)$ & $6 / 18$ & $100 \%$ & 5.0 & $100 \%$ \\
Total & 80 & NA & NA & $84 \%$ & 4.5 & $78.5 \%$ \\
\hline
\end{tabular}

S.S.: Short staircase

S.R.: Success rate

N.A.: Not applicable

1: One standard deviation

Table IV Summary of P.L. acuity data: clinical cases

\begin{tabular}{lcllc}
\hline Clinical diagnosis & $\begin{array}{l}\text { N. of } \\
\text { pts. }\end{array}$ & $\begin{array}{l}\text { Success } \\
\text { rate } \%\end{array}$ & $\begin{array}{l}\text { Mean test } \\
\text { Time each eye } \\
\text { L.S. (mins) }\end{array}$ & $\begin{array}{l}\text { Mean I.O.V. } \\
\text { (octaves) }\end{array}$ \\
\hline $\begin{array}{l}\text { Normals/suspected } \\
\text { abnormals }\end{array}$ & & & & \\
Strabismic & 9 & 64.3 & 9.4 & 0.50 \\
Miscellaneous & 19 & 79.3 & 7.3 & 0.36 \\
Total cases & 8 & 66.7 & 8.6 & 0.45 \\
\hline
\end{tabular}

L.S.: Long staircase

I.O.V.: Interobserver variations

The miscellaneous group included subjects with delayed visual maturation, congenital glaucoma, cataract, sixth nerve palsy, ptosis and congenital nystagmus. 
Three clinical cases who provided data on at least two occasions are presented.

\section{Case 1. (C.L.) (Fig. 7a)}

A 14 week old female infant presented with apparent failure to see. She was in good general health and was of normal development in other respects. PL acuities were recorded and found to be at least two octaves below the norm. Subsequent tests at 15 and 17 weeks revealed a rapid increase in acuity in both eyes. This trend was confirmed by independent clinical observations and suggests the diagnosis of delayed visual maturation.

Case 2. (G.T.) (Fig. 7b)

A 22 week old male infant was referred because of pendular nystagmus and suspected low vision and was found to have reduced PL acuity which improved over the next month, although remaining below normal. When re-tested at eleven months, acuity in the left eye had continued to improve while that in the right eye had deteriorated. Clinical examination revealed a marked right esotropia.

\section{Case 3. (K.J.) (Fig. 8)}

A thirteen month old female toddler showed a significant interocular acuity difference on PL testing with the score for the left eye within the age norm and that of the right approximately 1.5 octaves lower. A month later the acuity difference was insignificant. The clinical diagnosis was right esotropia and strabismic amblyopia and in the intervening period she had been prescribed glasses and had had occlusion for 8 hours daily to the left eye.

\section{Discussion}

Our experience with PL in clinical practice has shown that the method gives reliable and reproducible results when presented in the Teller Card format. The results of sequential examinations fit within the expected limits as predicted by the single point data. There are some studies reporting monocular acuity estimates using PL methods in vision research laboratories $(9,10,12,18)$ but only a few in clinical practice ${ }^{(19)}$, most using ACP. Our monocular acuity scores are in reasonable agreement. Our success rates are rather lower and variability of acuity scores wider than those reported by McDonald et al. The test times are comparable when using the short staircase. Our results probably reflect

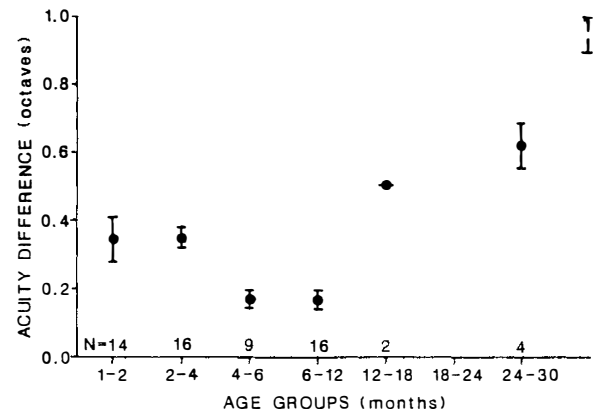

Fig. 6. Mean interocular acuity difference by age group.

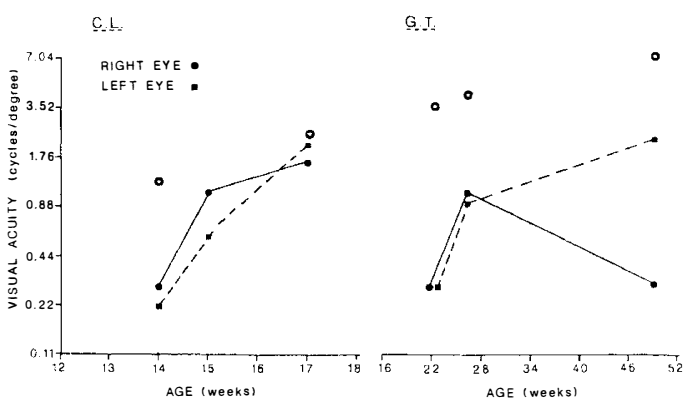

Fig. 7. $P L$ acuity results of Cases 1 and 2. Open circles represent mean normal acuity for age.

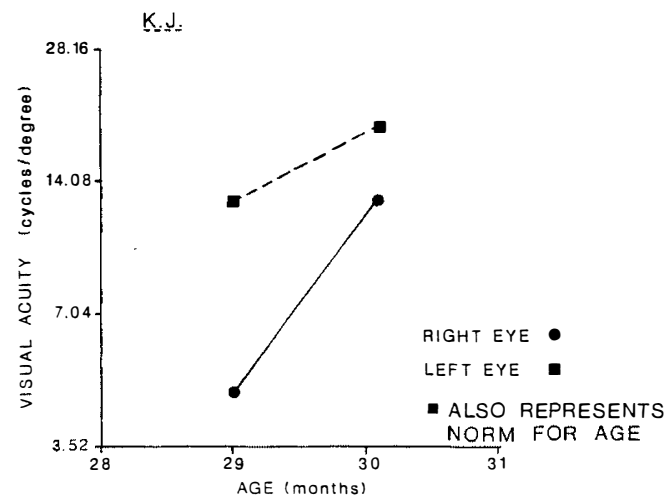

Fig. 8. PL acuity: Case 3.

those which will usually be obtained by PL in a clinical environment.

The abnormal cases we have examined have been readily identified on PL testing and in the case of delayed visual maturation the acuity trend obtained by PL testing was helpful in making the diagnosis. The effect of occlusion therapy in amblyopia is also detectable and thus monitoring by grating 
visual acuity is a possibility in the preverbal age group. There are some encouraging reports of using PL methods with face recognition stimuli ${ }^{(20,21)}$, which correlate well with the accepted clinical standard of Snellen acuity.

Considerable experience is required in order to become fluent with staircase procedures and with the kind of observations required in performing the test. Both the staircases we have described have given reliable results. In separate experiments we have shown that test-retest variability of the short staircase was greater than that of the long staircase (mean variation short staircase 1.0 octave; long staircase 0.36 octave) though these variations are not significant when compared to test-retest reliability of the PL procedure using the same method of presentation. (22) An important aspect for clinical practice is the average time taken to complete the test with each staircase: 8.3 minutes for the long and 4.5 minutes for the short, for each eye.

We feel that if the observer remains masked to the location of the grating, at least at the outset of each trial, then a valuable part of the objectivity of the test is preserved. Non-masked observers, especially without experience, may introduce bias in the results.

We have noted and investigated the presence of an "edge artefact" in the higher spatial frequency cards ( 13.0 to $38.0 \mathrm{cy} . / \mathrm{cm}$.) which may lead to the grating being detectable even when the stripes cannot be resolved. Our experiments show that this artefact is not present on the lower spatial frequency cards and does not interfere with the results in the age groups reported in this paper. However, we now use a screen with circular apertures which remove the artefact.

PL techniques suffer from the same limitations as any psychophysical test when applied to young children. Errors tend to occur in underestimating rather than overestimating acuity. ${ }^{(4)}$ One reason for this is a loss of interest in the grating as it approaches the infant's acuity threshold.

The use of PL techniques in clinical practice requires relatively inexpensive equipment but needs experienced staff and takes time to produce reliable results.
Despite these limitations, Preferential Looking offers the clinician a sensitive and useful method to detect and monitor visual deficits in the young child.

We wish to thank Dr. J. James and the Health Visitors at Montpelier Health Centre, Bristol. Our thanks to Ms. J. Galsworthy for typing the manuscript.

\section{References}

${ }^{1}$ Fantz RL: Pattern vision in young infants. Psychol Rec 1959; 8: 43-7.

${ }^{2}$ Fantz RL and Ordy JM: A visual acuity test for infants under six months of age. Psychol Rec 1959; 9: 159-64.

${ }^{3}$ Fantz RL, Ordy JM, Udelf MS: Maturation of pattern vision in infants during the first six months. J Comp Physiol Psych 1962; 55: 90717.

${ }^{4}$ Teller DY: The forced choice preferential looking technique for use with human infants. Infant Behaviour and Development 1979; 2: 135-53.

5 Mayer DL and Dobson V: Visual acuity development in infants and young children as assessed by operant preferential looking. Vision Res 1982; 22: 1141-51.

${ }^{6}$ Dobson V, Teller DY, Clifton PL, Wade B: A behavioural method for efficient screening of visual acuity in young infants. I - Preliminary laboratory development. Invest. Ophthalmol. Vis. Sci 1978; 12: 1142-150.

${ }^{7}$ Fulton AB, Manning KA, Dobson VA: A behavioural method for efficient screening of visual acuity in young infants. II - Clinical application. Invest Ophthalmol Vis Sci 1978; 12: 1151-57.

${ }^{8}$ McDonald MA, Dobson V, Sebris SL et al.: The Acuity Card procedure. A rapid test of infant acuity. Invest Ophthalmol Vis Sci 1985; 26: $1158-62$.

${ }^{9}$ McDonald MA, Sebris SL, Mohn G et al.: Monocular Acuity in normal infants. The Acuity Card procedure. Am J Optom Physiol Optics 1986; 63: 127-34.

${ }^{10}$ McDonald MA, Ankrum C, Preston $\mathrm{K}$ et al.: Monocular binocular acuity estimation in 1836 month olds: The Acuity Card procedure. $J$ Am Optom Physiol Optics 1986; 2: 181-86.

${ }^{11}$ Teller DY, McDonald MA, Preston K et al.: Assessment of visual acuity in infants and children : The Acuity Card procedure. Dev Med Child Neurol 1986; 28: 779-89.

12 Preston KL, McDonald MA, Sebris SL et al.: 
Validation of the Acuity Card procedure for assessment of infants with ocular disorders. Ophthalmology 1981 ; 65: 644-53.

${ }^{13}$ Atkinson J, Braddick O, Pimm-Smith E et al.: Does the Catford Drum give an accurate estimate of acuity? Br J Ophthalmol 1981; 65: $652-6$

${ }^{14}$ Dobson V: Clinical applications of Preferential Looking measures of visual acuity. Behav Brain Res 1983; 19: 25-38.

${ }^{15}$ Cornsweet TN: The staircase method in psychophysics. Am J Psychol 1962; 75: 48591.

16 Taylor MM, and Creelman CD: PEST: Efficient estimates in probability functions. $J$ Acoust Soc Am 1967; 4: 782-7.

17 Fellows BJ: Chance stimulus sequences for discrimination tasks. Psychol Bull 1967; 67: 87-92.
18 Atkinson J, Braddick $\mathrm{O}$ and Pimm-Smith E: "Preferential Looking" for monocular and binocular acuity testing of infants. $\mathrm{Br} J$ Ophthalmol 1982; 66: 264-8.

${ }^{19}$ Mohn G, van Hof-van, Duin J: Rapid assessment in infants and children in a clinical setting, using acuity cards. Doc Ophthalm Proc 1986; 45: 363-71.

${ }^{20}$ Harris SJ, Hansen RM, Fulton AB: Assessment of acuity in human infants using face and recognition stimuli. Invest Ophthalmol Vis Sci 1984; 25: 782-6.

${ }^{21}$ Harris SJ, Hansen RM, Fulton AB: Assessment of acuity of amblyopic subjects using face, grating and recognition stimuli. Invest Ophthalmol Vis Sci 1986; 27: 1184-7.

22 Birch EE: Infant interocular acuity differences and binocular vision. Vision Res 1985; 25: 4: $571-6$. 